\title{
A Review of In-Vivo and In-Vitro Real-Time Corrosion Monitoring Systems of Biodegradable Metal Implants
}

\author{
Priscilla Yin Yee Chin ${ }^{1}$, Quentin Cheok ${ }^{1}\left(\mathbb{D}\right.$, Adam Glowacz $^{2}\left(\mathbb{D}\right.$ and Wahyu Caesarendra ${ }^{1, *} \mathbb{C}$ \\ 1 Faculty of Integrated Technologies, University of Brunei Darussalam, Gadong BE1410, Brunei; \\ 16b4002@ubd.edu.bn (P.Y.Y.C.); quentin.cheok@ubd.edu.bn (Q.C.) \\ 2 Department of Automatic Control and Robotics, AGH University of Science and Technology, Al. A. \\ Mickiewicza 30, 30-059 Cracow, Poland; adglow@agh.edu.pl \\ * Correspondence: wahyu.caesarendra@ubd.edu.bn
}

Received: 29 March 2020; Accepted: 27 April 2020; Published: 30 April 2020

\begin{abstract}
In current modern medicine, biodegradable metal implants are still considered a work-in-progress between the collaborations of both scientists and engineers. As of now, one of the obstacles to this development is monitoring the corrosion rate of the implant. When a biodegradable metal implant (made of $\mathrm{Mg}, \mathrm{Zn}$, etc.) is introduced into the harsh environment of the human body, corrosion naturally occurs, causing metal ions to be released which may result in undesired health effects. The released products of the corroding implant can be used to monitor the implant condition. This paper discusses the current real-time corrosion monitoring systems (i.e., electrochemical-, microsensor-, and microdialysis-based) in-vivo and in-vitro. It is acknowledged that the progress in this sector still requires extensive research in order to obtain a desirable monitoring system and it is hoped that this review paper contributes to the research.
\end{abstract}

Keywords: in-vivo; real-time; corrosion monitoring; biodegradable metal implant; biomaterials; orthopedics; biodegradation

\section{Introduction}

In recent decades, materials engineers and scientists have spent considerable effort and time in conducting research in biodegradable materials. Some may argue that the field of biomaterials possibly began 4 millennia ago when the Egyptians and Romans utilized gold and iron for applications in dental issues and performed toe replacement surgeries with wood without considering the problem of corrosion. The significance of this field has gained prominence after the world wars as the demand for biomaterials was rising [1]. An estimated 8 million fracture-related injuries are reported in the United States annually and a rising cost of US $\$ 116$ billion has been forecast for the bio-implants market by 2020 [2]. There is no doubt that the field of biomaterials plays a significant role in increasing the mobility and lifestyle of a significant portion of the world's population.

Study on biodegradable materials can generally be divided into two main categories i.e., (1) biodegradable metal implants and (2) biodegradable non-metal implants. The example of the biodegradable metal implant is discussed in this paper whereas an example of biodegradable non-metal implants (e.g., bioceramic and polymers) has been discussed elsewhere [3]. The concept of a biodegradable metal implant is that it should be able to degrade in an in-vivo (human/animal body fluid) setting at an appropriate rate without any toxic effects to the host body. In addition, the metal implant must be able to uphold its durability while aiding the patient's recovery. Once the healing process is completed, the implant should then ideally dissolve as soon as new tissues are developed [4]. 
There are currently three well-studied materials utilized in biodegradable implants: magnesium, iron, and zinc. These biodegradable implants have been utilized in useful medical applications such as coronary stents, bone screws, pins, plates, and such (Figure 1) due to their ability to integrate with human cells and tissues [5].

Although the biodegradable non-metal implant has shown to be more appropriate in practice however, clinical trials are needed before this material can be applied for human use. In contrast with the non-metal option, the biodegradable metal implant is more applicable in a shorter period of time for human applications. Meanwhile, the real-time or rapid corrosion monitoring has remained unsolved. The current method of corrosion monitoring involves performing a subsequent surgical procedure to observe whether there are any chemical reactions between human tissue and the biodegradable metal implant. This risky and potentially fatal issue has motivated the authors to write a review paper regarding existing real-time corrosion monitoring methods. In addition, this is a preliminary study of the development of real-time corrosion monitoring for biodegradable metal implants.
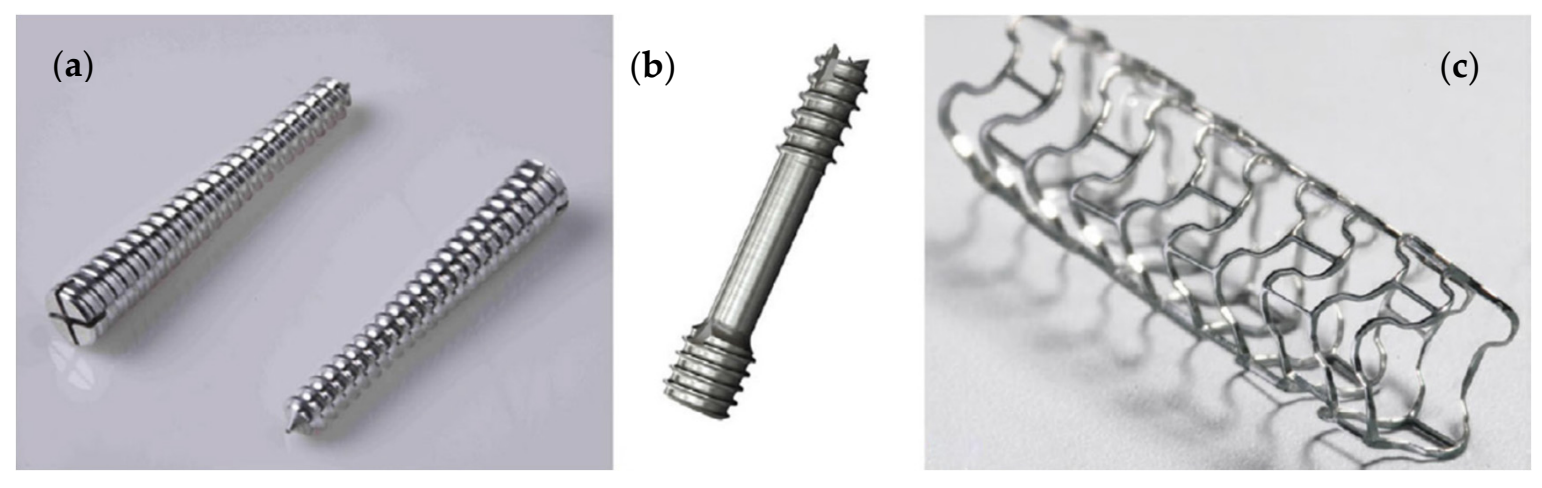

Figure 1. Examples of biodegradable metal implants: (a) headless screws developed by U\&ICorporation, Korea, (b) compression screw from a German company; and (c) a biodegradable stent designed by a German company [2].

\section{Biodegradable Metals and Their Alloys}

The most basic criteria for choosing a biomedical device is from observing the compatibility response of the body tissues towards the device [1]. Hence, the most commonly-used biodegradable metals are iron, magnesium, zinc, and their alloys. Not only are these metals compatible with the human body, but are also considered essential elements for the body to function properly. The corrosion rate of iron is usually lower than that of magnesium while zinc corrodes at a rate between iron and magnesium and lastly, magnesium being the quickest to corrode as evident by Vojtech et al. [5] where a comparison of their corrosion rates can be arranged in an ascending order with pure iron, pure zinc, and pure magnesium corroding at rates of $0.2,0.6$, and $4 \mathrm{~mm} /$ year respectively after immersion in a $37^{\circ} \mathrm{C}$ saline solution for $168 \mathrm{~h}$.

Iron is considered as one of the essential elements to allow for normal function inside the human body as it plays an important role of in the transport of oxygen [6]. Its daily intake allowance is set at $20 \mathrm{mg}$ [2]. Exceeding this amount would generate lesions in the digestive tract, induce pain in the abdominal area, cause fatigue, as well as harm the liver [7]. One of the benefits of utilizing iron as a biodegradable metal implant is its mechanical property which is similar to that of $316 \mathrm{~L}$ stainless steel, which is the actual base standard for biomaterials involving metals. The superior mechanical properties of pure iron compared to pure zinc and pure magnesium makes it an appropriate candidate for constructing implants that require significant structural strength such as coronary stents [5]. In addition, when a complex iron phosphate layer is formed, it causes iron to very slowly degrade in-vivo. Several attempts have however been made to increase its corrosion rate by alloying it with manganese and palladium or adopting a vapor vacuum arc technique to implant silver. Additional efforts such as 
making it composites with its oxides or bioceramics have shown minor improvement towards iron's bioactivity [2].

Zinc is considered the latest addition proposed as a biodegradable metal [5] based on its vital function in numerous enzymes and cell metabolic activities, cell reproduction, and cellular differentiation. Its daily allowance is the lowest compared to iron and magnesium which is at $15 \mathrm{mg}$. In excessive amounts, it poses a threat of neurotoxicity, muscle cramps, diarrhea [8], anemia, and reduced bone formation [6]. The compatibility of zinc-based metals amongst cells has been studied to evaluate its application for bone and vascular implants. The physical properties (i.e., toughness and flexibility) of zinc can be improved by alloying it with a small amount of magnesium (up to $3 \mathrm{wt}$. \%) and further enhanced by adopting severe plastic deformation processing techniques [2] or through thermomechanical treatment (e.g., extrusion) [5]. Since it is relatively new, further research is required to upgrade its ultimate tensile, compressive and yield strengths in order to improve their function in surrounding tissues [9].

Magnesium is the lightest engineering metal possessing a mass to volume ratio of $1.74 \mathrm{~g} / \mathrm{cm}^{3}$ [10] and has a low ratio of force, about 40 to $45 \mathrm{GPa}$ exerted on the body which is similar to that of human bone [5] making it compatible with bone tissues [11]. Similarly to the aforementioned two metals, it is also an essential element but with a higher intake tolerance level of up to $700 \mathrm{mg}$ and the ability to mimic a protein coagulator, magnesium has influence in numerous bodily reactions involving enzymes [2]. However, exceeding the daily intake causes hypermagnesemia which is linked with diseases such as arrhythmia and asystole. In addition, corroding magnesium creates hydrogen bubbles which have the potential to clog blood vessels, resulting in death [9]. Other side effects include nausea, kidney failure, and ineffective breathing [8]. When utilizing a biodegradable metal implant that is constituted of the alloys of magnesium, an advantage is that there is no presence of unwanted side effects from stress shielding which would otherwise occur in common implants made of metals [12]. It is these factors that permits magnesium to be a material that is osteoconductive [13]. However, there are challenges when adopting a magnesium-based implant due to its relatively low strength and ductility along with the production of hydrogen gas during its degradation. Further improvement on the properties of magnesium-based metals can be accomplished by advanced alloying (e.g., with calcium, zinc, zirconium, and rare earth metals), purifying the metal from impurities such as copper and nickel, switching its microstructure to nanocrystalline and amorphous state [2] and utilizing treatments such as thermomechanical treatment and severely deforming the material [5]. As opposed to iron, applying a coating on the surface of magnesium with bioceramics or biopolymers can delay its corrosion rate [2]. Being the eighth most plentiful element present in the earth's crust [10] has earned its place in being the most researched amongst all the three biodegradable metal materials [5]. This is mainly due to the fact that the requirement for a secondary removal surgery is not compulsory with the assistance of such material [14]. Comparisons between all three biodegradable metals are summarized in the table below (Table 1). 
Table 1. Summary comparison of the three biodegradable metals for implants. * Corrosion rate data obtained from identical experiments, i.e., conducting polarization test in $37^{\circ} \mathrm{C}$ simulated body fluid. Values might change depending on testing condition and parameters.

\begin{tabular}{|c|c|c|c|}
\hline Category & Magnesium & Zinc & Iron \\
\hline Applications & $\begin{array}{l}\text { Tissue engineering, orthopedic (e.g., hip joints, } \\
\text { screws/pins and dental implants [8]), micro } \\
\text { clips for laryngeal microsurgery and } \\
\text { cardiovascular applications [3]. }\end{array}$ & \multicolumn{2}{|c|}{ Vascular and orthopedic applications [9]. } \\
\hline Corrosion rate & Fastest & Medium & Slowest \\
\hline Modulus/GPa [2] & $\begin{array}{c}30 \text { (Pure Mg) } \\
45 \text { (Mg-Based) }\end{array}$ & $\begin{array}{c}60 \text { (Pure Zn) } \\
100 \text { (Zn-Based) }\end{array}$ & $\begin{array}{c}150 \text { (Pure Fe) } \\
200 \text { (Fe-Based) }\end{array}$ \\
\hline Tensile Strength/MPa [5] & 100 (Pure Mg) & 90 (Pure Zn) & 200 (Pure Fe) \\
\hline Maximum elongation/\% [5] & 7 (Pure Mg) & 8 (Pure Zn) & 40 (Pure Fe) \\
\hline Corrosion rate $* /(\mathrm{mm} /$ year $)[5]$ & 8 (Pure Mg) & 0.16 (Pure Zn) & 0.1 (Pure Fe) \\
\hline Strengths [9] & $\begin{array}{c}\text { Its alloys are compatible with the human body } \\
\text { and have elastic moduli, strength and } \\
\text { compressive strength that are similar to } \\
\text { trabecular bone. }\end{array}$ & $\begin{array}{c}\text { Anti-inflammatory and anti-proliferative } \\
\text { properties. Effective in reducing risk of } \\
\text { atherosclerosis. }\end{array}$ & $\begin{array}{l}\text { Fe stents have promising } \\
\text { mechanical properties and } \\
\text { biocompatibility [15]. }\end{array}$ \\
\hline Weaknesses [14] & $\begin{array}{l}\text { Quickly corrodes before complete tissue } \\
\text { reconstruction due to lack of resistance to } \\
\text { chloride elements present in the bodily fluids. }\end{array}$ & $\begin{array}{l}\text { Compared to other alloys, it suffers from } \\
\text { very low radial strength. }\end{array}$ & $\begin{array}{l}\text { Corrodes excessively slowly to be } \\
\text { practical for bioresorbable } \\
\text { applications. }\end{array}$ \\
\hline Solution [9] & $\begin{array}{l}\text { Surface treatment to reduce corrosion rate. } \\
\text { Potential techniques such as alkaline heat } \\
\text { treating, microarc oxidation (e.g., FHA/MAO } \\
\text { coated Mg implant [16]), calcium phosphate } \\
\text { deposition, fluoride treatment [17], electro } \\
\text { deposition and polymer coating can be used. }\end{array}$ & $\begin{array}{l}\text { Considering that zinc is relatively new to } \\
\text { the biodegradable metal family, further } \\
\text { studies are required to conclude its } \\
\text { potential as vascular scaffold and in } \\
\text { orthopedic applications. }\end{array}$ & $\begin{array}{l}\text { Alloy elements such as manganese } \\
\text { to increase iron's corrosion rate. }\end{array}$ \\
\hline
\end{tabular}




\section{Correlation of In-Vitro and In-Vivo Corrosion}

Prior to the analysis of the corrosion behavior of a specimen in its test environment, there are difficulties faced when it comes to mimicking in-vivo conditions in the in-vitro tests. This is because corrosion behavior such as local inflammation and tissue-implant interactions are influenced by a significant amount of factors inside the human body. Such factors are challenging to implement through in-vitro corrosion tests [18]. As performed by Witte et al. [19] when analyzing the corrosion rate of magnesium alloys, the rate of corrosion obtained from in-vivo tests were only smaller in magnitude by four orders compared to those obtained from in-vitro tests. One of the most problematic issues associated with magnesium and its alloys is their unpredictable corrosion behavior in-vivo mainly due to the fact that there are numerous other ions present within the body fluids (e.g., $\mathrm{Na}^{+}, \mathrm{K}^{+}, \mathrm{Ca}^{2+}$, etc.) which makes metallic corrosion prediction a complicated task [20].

Meanwhile, there are cases where the corrosion rate of a magnesium alloy (XHP Mg) performed in-vitro (immersion tests) compared well with in-vivo studies (implantation into the femurs of rats) as their degradation rate were almost similar. However, the consistency of results of these reported experiments, performed either in-vivo or in-vitro may not be comparable for all alloyed materials because corrosion behavior is influenced not solely on the composition of the electrolyte but also significantly affected by the interactions between the material and the type of electrolyte used [21]. Furthermore, due to the complexity and diversity of the human body internal environment, different evaluation procedures should be carried out for implants located in different areas of the body. To elucidate an example, one study attempted to examine the corrosion behavior and biocompatibility of hydroxyapatite (HAp) and octacalcium phosphate (OCP) coatings on AZ31 alloy by performing an immersion test for a long period of time in a medium (in-vitro) and by implantation test in transgenic mice (in-vivo) [22]. The surfaces of both alloy samples were examined and characterized with the assistance of an optical microscope (OM), backscattered scanning electron microscopy (BSEM), energy dispersive spectroscopy (EDS), X-ray power diffraction (XRD), and grazing incidence X-ray diffraction (GIXD). It was observed that the corrosion in-vitro was macroscopically-localized while microscopically-localized in-vivo. Whereas for the coating composition, in-vitro, the OCP and HAp coatings showed more precipitation of HAp while in-vivo, the HAp crystals dissolved locally. This shows that the test environment either in-vivo or in-vitro should be carefully designed to determine the corrosion behavior of OCP and HAp coatings [22]. At this present stage, it is even acknowledged that completely mimicking the corrosion behavior of an implant in the human body through in-vitro corrosion test is still a challenging task [18].

In Wen et al.'s study [23], they developed a type of relationship between in-vivo and in-vitro called IVIVC (in vitro and in vivo correlation) to assist in screening new materials and monitor the quality of the devices in-vitro for ethical reasons involving protection of animals and reducing the time-consuming process of in-vivo experiments, which has a duration of months or years. While the experiment outcome proved promising, additional improvements are still required to be carried out. Lastly, the established IVIVC still needs to be corroborated by other researchers. To further emphasize the importance of correlating the two test conditions, Ulum et al. [4] has stated that in order for researchers to compare their results easily, a standard method is needed to evaluate how certain parameters exactly influence the in-vitro corrosion of a metal.

\section{Compromise between Mechanical Integrity and Degradation Rate}

As mentioned previously, the purpose of a biodegradable metal implant is to assist in the patient's healing process by providing mechanical support to the injured area and then biodegrading away thereafter. As certain medical issues only require a temporary aid for eventual healing (e.g., cardiovascular, orthopedic, and pediatric care), the requirement for a metal implant is to have a non-permanent presence. In ideal cases, a biodegradable metal implant would have an optimal middle ground between keeping its mechanical integrity for a certain duration and thereafter, progression of its deterioration after a period of time, as represented in Figure 2. 
After implantation, the inflammatory process (i.e., swelling of the bone's fractured vessels) begins within a day to a week after fracture. Then, new connective tissues, blood vessels, cartilage and soft spongy bone begin to develop a soft callus within 2 to 6 weeks. By the 12th week, osteoblasts would have already caused the soft callus to harden [24]. The hard callus stage ends when the fragments are firmly healed by a new woven bone, typically within 3 to 4 months. The time taken for the fracture healing period is dependent on the fracture site (i.e., bones located in the lower limbs would take a longer time to heal as their sizes are larger). The recovered bone will continue to remodel itself over the next period of months or years as a result of the stresses derived from physical activity. It is expected that the biodegradable metal implant should retain its mechanical integrity until this stage. The woven bone, via the osteonal remodeling process, will be gradually substituted by the lamellar bone, returning the bone to its original morphology. For different applications (e.g., stents), they should have different mechanical integrity and predicted corrosion rate to accommodate the healing process $[2,24]$. For example, a coronary stent made from a magnesium alloy is expected to last for a period of 6-12 months during the process of remodeling the blood vessel, and then completely degrade in the next 12-24 months. Meanwhile for orthopedic biomaterials, 3-4 months is needed from the formation of fracture callus to the formation of new bone, which leads to the eventual solidification of the bone thus, restoring a majority of the bone's intrinsic strength [14].

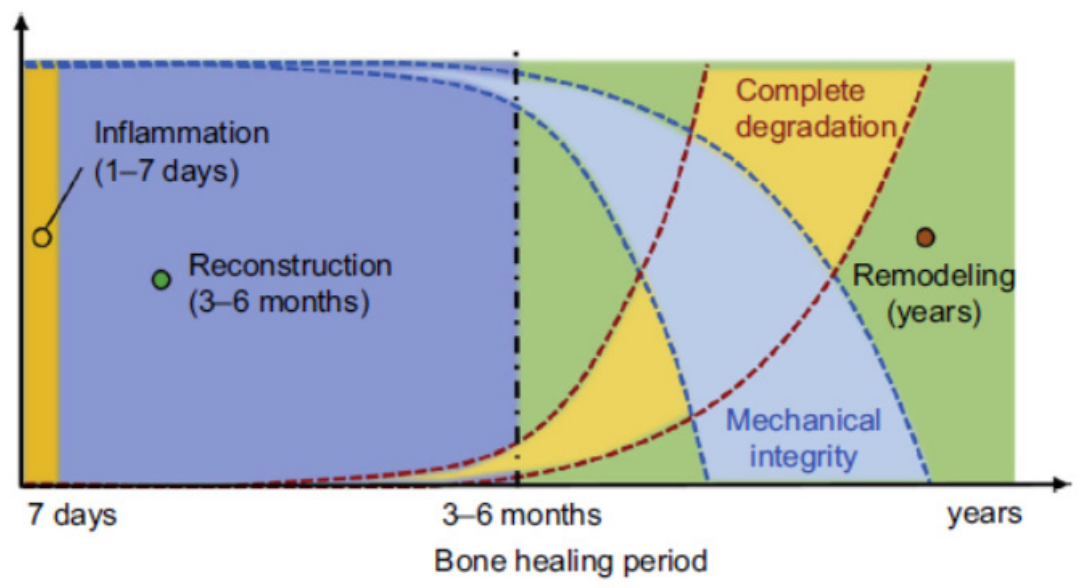

Figure 2. Ideal balance between an implant's mechanical integrity and corrosion rate [2].

\section{Implant-Tissue Interaction during In Vivo Corrosion}

After implantation has been performed, there is continuous interaction between the biodegradable metal implant and the extracellular tissue fluid. For this reason, an electrochemical dissolution of the biodegradable metal implant occurs. This causes a continual process of protein absorption, coagulation, acute, and chronic as a result of the body response to a foreign entity. All these biological processes occur right after implantation thus, inducing space between the implant and tissues to be filled with body fluid. After the first week of post-implantation, cellular inflammation follows which decreases after a period of time, followed by surrounding tissue proliferation to fill the interspace [2].

An illustration of a biodegradable metal interacting with the local tissue followed by the response of the body is presented in Figure 3. Corrosion begins after implantation, and then, the tissue responds to the foreign object. Corrosion products are formed and discharged into the tissue at various sizes; the blood cells transport these products into several other tissue areas depending on location of implant (e.g., muscle skin, bone, etc.) [3]. 


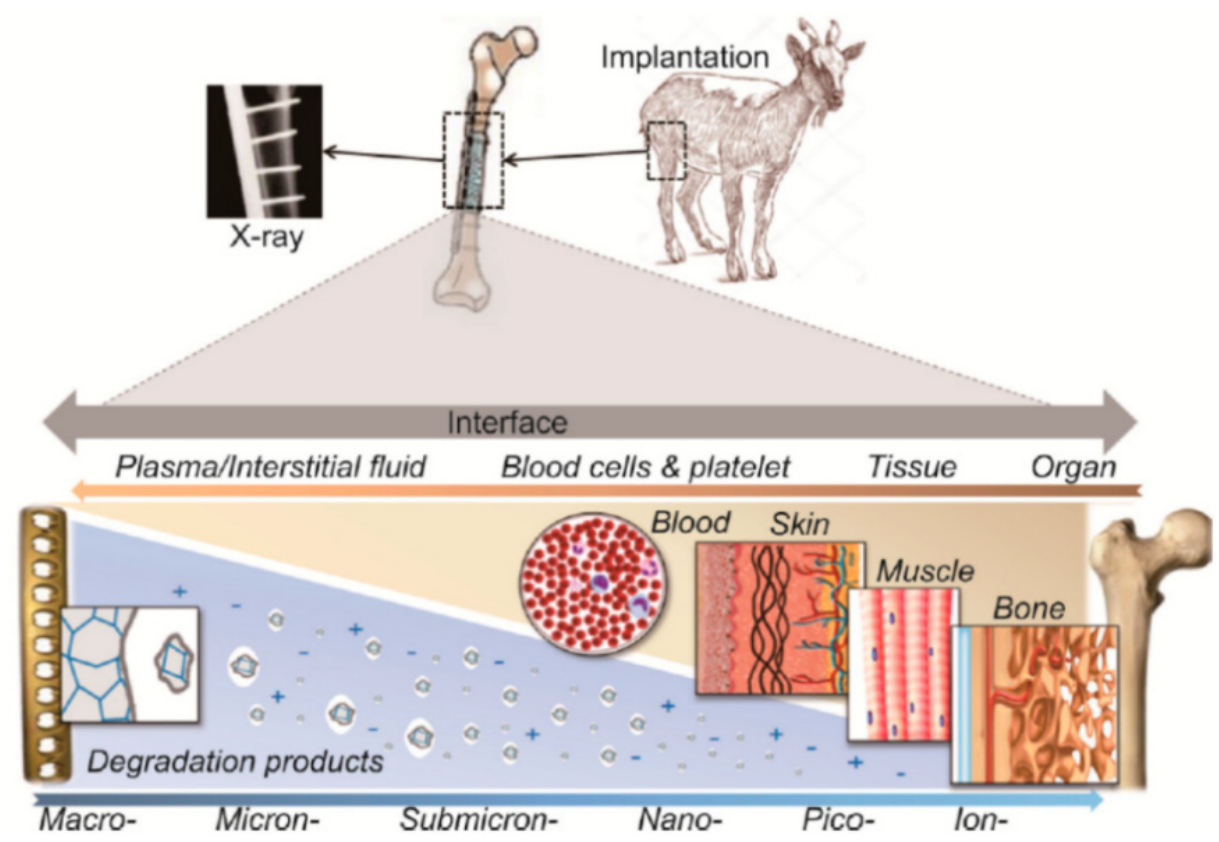

Figure 3. Illustration of biodegradable metal interacting with the local tissue, followed by the body's response [4].

Corrosion occurs when a material gradually deteriorates after undergoing electrochemical reactions as a result of being placed in the body's harsh electrolytic environment. The fluid medium in the body is made up of various anions, cations, and other components. Biological molecules, such as proteins, interfere with the equilibrium of corrosion reactions by binding themselves to the ions discharged from the metal whereas those absorbed on the surface reduce the oxygen diffusion at certain regions thus, causing corrosion [1]. In general, corrosion stems from either metal imbalance such as phase variation, grain boundaries, and impurities or from shape and environmental changes such as crevices, scratches, defects in coating, amount of oxygen, and others. For a metal (M), the general corrosion reactions that would occur in a physiological environment is represented below [4]:

Anodic reaction:

$$
\mathrm{M} \rightarrow \mathrm{M}^{\mathrm{n}+}+\mathrm{ne}^{-}
$$

Cathodic reaction:

$$
2 \mathrm{H}_{2} \mathrm{O}+2 \mathrm{e}^{-} \rightarrow \mathrm{H}_{2}+2 \mathrm{OH}^{-}
$$

or

$$
2 \mathrm{H}_{2} \mathrm{O}+\mathrm{O}_{2}+4 \mathrm{e}^{-} \rightarrow 4 \mathrm{OH}^{-}
$$

Product formation:

$$
\mathrm{M}^{\mathrm{n}+}+\mathrm{nOH}^{-} \rightarrow \mathrm{M}(\mathrm{OH})_{\mathrm{n}}
$$

The physiological solution comprises numerous discharged ions, dissolved oxygen, organic compounds, proteins, and other components. These ions discharged from metal will interact with water and other species to construct a corrosion product layer (e.g., metal hydroxides or metal complexes as illustrated in Figure 4). Simultaneously, water reduction and/or oxidation by electrons released from the metal causes the formation of hydrogen gas or hydroxide ions. Surrounding the implantation site will be a decrease in $\mathrm{pH}$ in the range of 5.3 to 5.6 because of the inflammatory response which accelerates the corrosion rate of the metal and reduces the local oxygen concentration. For inorganic ions such as $\mathrm{Cl}^{-}$, decomposition of $\mathrm{M}(\mathrm{OH})_{n}$ layer occurs, resulting in perpetual and localized corrosion attack. This effect is similar for $\mathrm{SO}_{4}{ }^{2-}$ whereas other ions such as $\mathrm{HPO}_{4}{ }^{2-} / \mathrm{PO}_{4}{ }^{3-}$, $\mathrm{HCO}_{3}{ }^{-} / \mathrm{CO}_{3}{ }^{2-}$, and $\mathrm{Ca}^{2+}$ help to protect magnesium and iron due to the precipitation of phosphate and carbonate salts on the surface of the metal. Other methods of protection involve delaying the 
corrosion of magnesium by the adsorption of organic molecules (e.g., albumin) onto the surface of the metal or reducing the obstacles faced by the insoluble salt layer against decomposition of magnesium by utilizing amino acids [2].

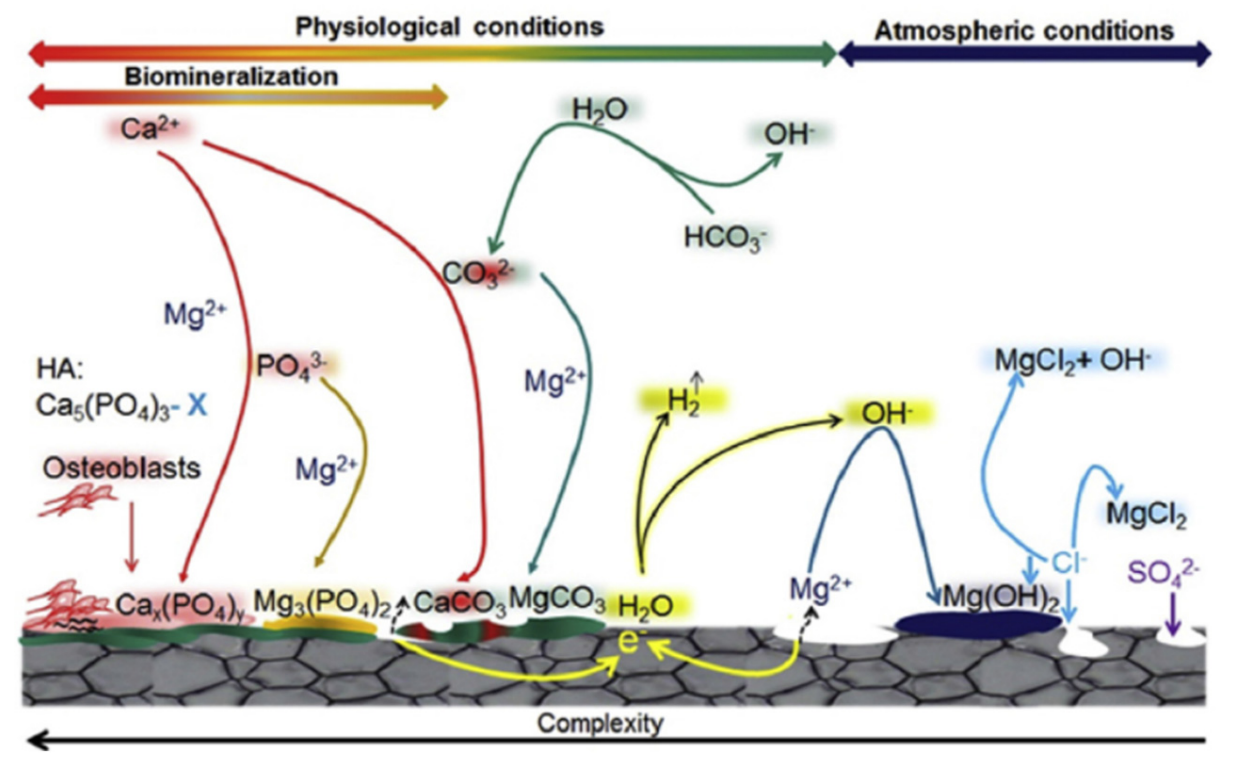

Figure 4. Production of numerous corrosion products in a physiological environment [8].

\section{Real-Time In-Vivo and In-Vitro Corrosion Monitoring}

Real-time corrosion monitoring refers to any process that monitors the corrosion of in-vivo/in-vitro biodegradable metal implants which allows for the results to be obtained immediately during the measurement. It is typically done by combining two different methods of corrosion monitoring. For example, pairing radiography with an image processing software or inspecting blood samples online with mass spectroscopy [2]. Since the corrosion of metals is a real-time dependent process, it cannot be ideally observed using techniques such as implant retrieval, histology analysis, etc. [4]. However, there are ways to evaluate the corrosion behavior of the biodegradable implant in real-time; these can be classified into: electrochemical-, biosensor-, and microdialysis-based monitoring systems.

\subsection{Electrochemical-Based Monitoring System}

The electrochemical-based monitoring system typically analyzes the behavior of the analyte during the corrosion process of the metal. [4]. Normally, a metal would be placed in an aggressive environment, inducing corrosion products to form. If the environment is an electrolyte, two processes would occur, one of which is an anodic process; where the metal undergoes oxidation and the other of which is a cathodic process; where a reduction reaction would occur such as oxide or hydroxide ion reduction. The cations and anions will move in opposite directions, resulting in an electric current being generated within the metal [25]. The electric current can then be transformed and measured as electric potential (voltage). One way of measuring voltage is by setting up three electrodes namely, the working electrode, reference electrode, and counter electrode immersed in the electrolyte; this results in an amperometric sensor circuit (Figure 5a) [4]. The application of three electrodes allows a more precise measurement outcome, usually achieved by passing little or no current through the reference electrode [26]. Another option of measuring voltage is to have an electrochemical cell connected to a potentiostat, also known as the potentiostat circuit (Figure 5b) [4]. 


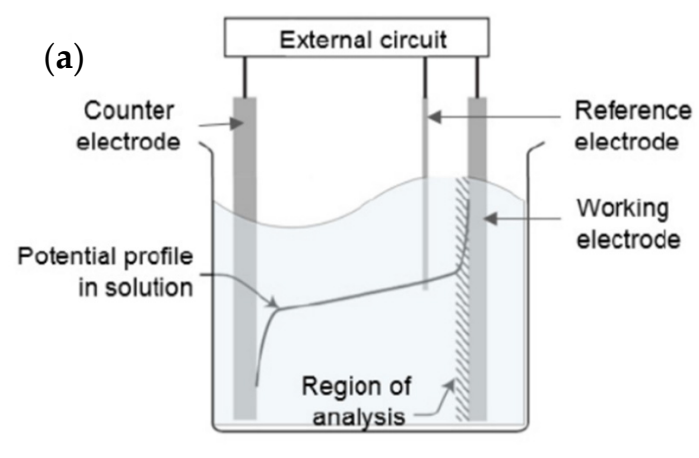

(b)

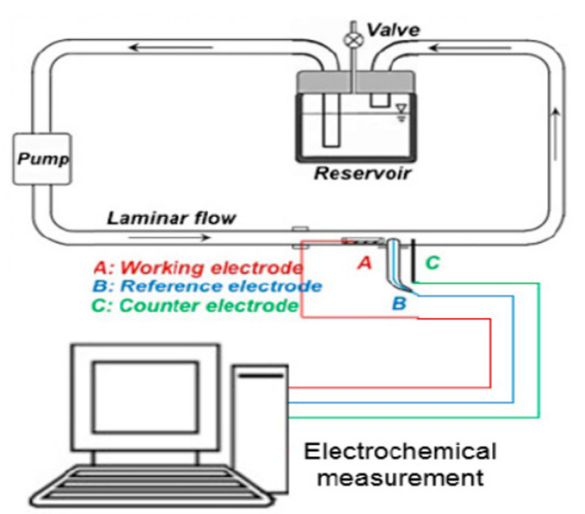

Figure 5. (a) An amperometric sensor circuit; (b) An experimental setup to monitor corrosion of biodegradable metal alloy [4].

Wang et al. [27] adopted this method when conducting research into the vascular bioreactor (Figure 5b) in order to examine the corrosion of the $\mathrm{Mg}$ metal alloy in real-time. Since the material was used for constructing vascular stents due to its in-vivo potential, the experimental set-up of the vascular bioreactor consisted of Tygon tubing as a channel for testing, the electrolyte, Dulbeco's modified Eagle's medium (DMEM), a flow pump for varying the flow rate, a reservoir, and an incubator. This set-up mimics actual physiological conditions that would be encountered in blood vessels. The potentiostat used in this experiment performs electrochemical impedance spectroscopy (EIS), open circuit potential (OCP), and linear polarization measurement (LPM). To differentiate their study from other Mg electrochemical studies, the approach taken was to observe the corrosion mechanism of $\mathrm{Mg}$ affected by forces exerted from fluids in a real-time scenario. This is because, in this type of environment, a more reliable result is obtained from the in-situ data. It can be concluded that in order to determine corrosion in the long term, EIS is a suitable and non-harmful candidate that allows continuous monitoring. In addition, the EIS can provide quantitative data of the corrosion process at the interface of the electrolyte-electrode along with any changes in electrode.

Corrosion characterization system (CCS) is also another approach adopted from electrochemical-based principles. Doepke et al. managed to create a CCS that allows monitoring in real-time by analyzing the soluble corrosion products such as $\mathrm{OH}^{-}, \mathrm{Mg}^{2+}$, and $\mathrm{H}_{2}$ in the solution during immersion tests [28]. Their study involved combining several methods to monitor the corrosion of $\mathrm{Mg}$ continuously in real-time during immersion tests (Figure 6). The real-time methods that they used involved using a glass $\mathrm{pH}$ electrode, a water hardness ion-selective electrode (ISE) and a platinum disk sensor to continuously measure the concentration of hydroxide ions, magnesium ions and dissolved hydrogen, respectively. Very small implantable sensors such as an $\mathrm{Mg}$ ion selective electrode can be fabricated by infusing an ionophore with a selectivity towards $\mathrm{Mg}$ ions in a liquid membrane [29]. The simultaneous usage of multiple electrochemical sensors for measuring corrosion products in a solution is one of the attractive features of CCS. Furthermore, CCS can also evaluate whether protection from corrosion in the form of coatings formed on the surface reduces the rate of corrosion of the metal. The Faradaic and non-Faradaic impedance changes at the metal-solution interfaces were monitored by EIS measurements. At low frequencies, the Faradaic impedances occur from the redox reactions of corrosion while at high frequencies, the non-Faradaic impedances are monitored through surface charging and obstruction by degraded products or passivation. After the immersion tests were completed, the results were analyzed using atomic absorption spectrometry (AAS) to determine the concentration of $\mathrm{Mg}$ present in the solution. The limitations of this method was potential interference by other ions or simultaneous usage of potentiometric sensors and EIS instrumentation [28]. In addition, the electrode life affects the EIS technique for in-vivo recording. As time passes, its quality and accuracy deviates [4]. 


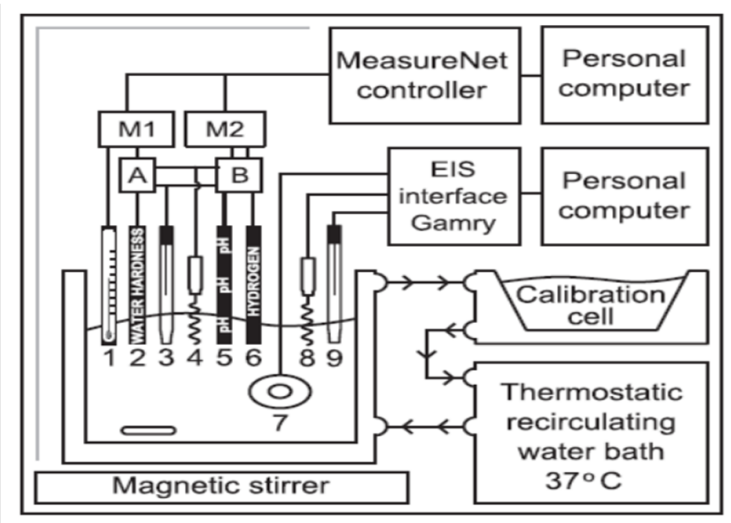

Figure 6. CCS system instrument and cell layout. (1) Temperature instrument, (2) Sensor for water hardness, (3) Reference electrode, (4) Pt solution ground, (5) $\mathrm{pH}$ sensor, (6) $\mathrm{H}_{2}$ sensor, (7) Working electrode, (8) Pt auxiliary electrode, (9) Reference electrode, A, B, pre amplifiers; M1, M2, MeasureNet workstations [28].

In another study [30], electrochemical methods complemented with real-time imaging technique were adopted to observe the magnesium corrosion in order to determine the local processes as well as the evolution of hydrogen gas. The magnesium specimen used for testing and plan view imaging was exposed to six different electrolytes. A layout of three electrode cell was selected where the working electrode was the magnesium specimen while the reference electrode and counter electrode are calomel electrode and platinum wire, respectively. They performed a potentiodynamic polarization test in which measurement was obtained after three minutes of immersion in the test solution. It was proposed that disruption of the oxide/hydroxide film was caused by the generation of streams of bubbles when an anodic current is available along with environmental conditions that induce depassivation. As a result of the direct exposure of electrolyte and $\mathrm{Mg}$ specimen, as well as the larger overpotential due to release of hydrogen bubbles, the corrosion front amplified the current where oxidation rate of magnesium is proportional to the total 'remote' anodic current (linked to the evolution of medium to large bubbles) and local anodic current (linked to the streams of hydrogen).

Figure 7a,b represents the six different anodic and cathodic polarization curves. Based on the diagrams, their passive behavior is analyzed. Both curve A and B showed passive behavior in the anodic region indicating presence of a protective film on their surfaces. Despite chloride ions being present (from curve B's electrolyte solution), there was no significant effect during the whole anodic polarization on the passive film. With a lower concentration of electrolyte (curve $C$ and $D$ ), curve $C$ exhibits a passive behavior while curve $D$ represents a very small passive region followed by a quick rise in current density. As for the remaining last two curves (curve $\mathrm{E}$ and $\mathrm{F}$ ), the current densities observed for curve E at anodic and cathodic polarization is lower than that of curve F's. This is due to the chloride ions disrupting the protective film. Real-time imaging work was also conducted during potentiodynamic polarizations for certain electrolytes (e.g., $0.01 \mathrm{M} \mathrm{NaOH}$ ) to comprehend the mechanism of hydrogen evolution on magnesium [30]. In general, measurements of potentiodynamic polarization can help determine the instantaneous corrosion rate $\left(\mathrm{i}_{\text {corr }}\right)$ at the corrosion potential, $\mathrm{E}_{\text {corr }}[10]$.

During the corrosion process, the surface released hydroxyl ion and metallic ions as cell growth has different stages, depending on the distance from the sample. Due to the progress in technology, two methods have been developed which makes the investigation of corrosion current density and ion distribution at microscopic spatial resolution possible throughout the corrosion process. These two methods are scanning vibrating electrode technique (SVET) and scanning ion-selective electrode technique (SIET). A study conducted by Yang et al. [31] used SVET and SIET with two representative 
intermetallic phases, $\mathrm{Mg}_{2} \mathrm{Ca}$ and $\mathrm{MgZn}_{2}$ to measure corrosion process differences present in $\mathrm{Mg}-\mathrm{Mg}_{2} \mathrm{Ca}$ and $\mathrm{Mg}-\mathrm{MgZn}_{2}$ through current density, $\mathrm{pH}$ value and magnesium ions concentration.
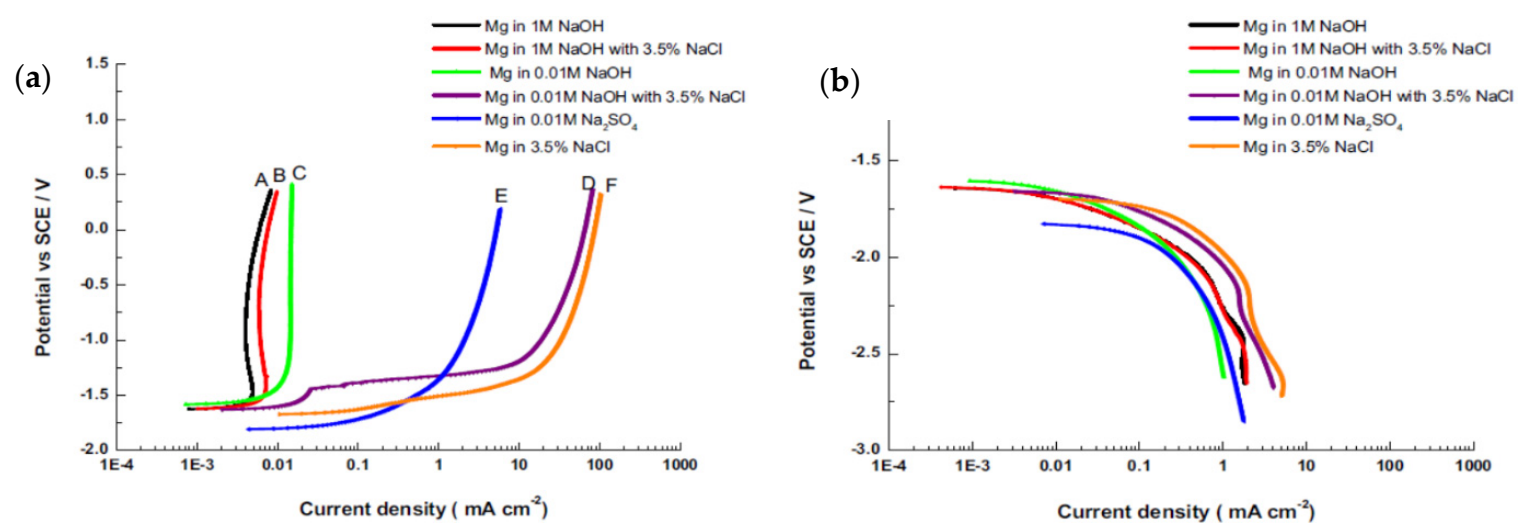

Figure 7. (a) Anodic polarization curves; (b) cathodic polarization curves [30].

All in all, methods for corrosion monitoring that is associated with electrochemical techniques include potentiodynamic polarization, potentiostatic polarization, galvanostatic and galvanodynamic polarization, and electrochemical impedance spectroscopy. Furthermore, methods composed of localized electrochemical technique consist of scanning vibrating electrode technique, scanning electrochemical microscopy (SECM), and atomic emission spectroelectrochemistry (AESEC) [10].

The set-up that Zhao et al. developed [32] used CCS to perform real-time corrosion monitoring of $\mathrm{Mg}$ with an upgrade by creating a new generation of CCS with home-made capillary $\mathrm{pH}$ and $\mathrm{Mg}^{2+}$ electrochemical sensors, where the main advantage of the $\mathrm{pH}$ microelectrode is its compatibility with the human body, making it helpful for cell biology applications or small volume experiments. The fabricated electrodes based on glass capillaries for $\mathrm{pH}$ and $\mathrm{Mg}^{2+}$ had the ability to detect differences in $\mathrm{pH}$ and $\mathrm{Mg}^{2+}$ during corrosion of $\mathrm{Mg}$ in $\mathrm{NaCl}$ solution. EIS was combined with the sensor to allow for real-time corrosion monitoring during immersion tests without the need for removal of the solutions for offline observation. It was observed that the capillary microsensors for $\mathrm{pH}$ and $\mathrm{Mg}^{2+}$ were deemed successful for Mg corrosion real-time measurement [32].

\subsection{Microsensor-Based Monitoring System}

A microsensor-based monitoring system was first created by Zhao et al. [33]. The experiment was carried out on mice to test the reliability of transdermal $\mathrm{H}_{2}$ measurements with the assistance of a biosensor that is highly sensitive to hydrogen (Figure 8). The measurements were recorded by ensuring the $\mathrm{H}_{2}$ microsensor's sensor tip touched the skin above the gas cavity at the implanted area. The sensor measures the current and is converted to regional $\mathrm{H}_{2}$ concentration using a calibration curve generated from known levels of $\mathrm{H}_{2}$ saturated water. Further analysis is then carried out using X-ray photoelectron spectroscopy (XPS) and inductively coupled plasma mass spectrometry (ICP-MS). The limitation of this set-up is its dependency on the high permeability of hydrogen leaving the skin, which is potentially a problem when monitoring the corrosion of $\mathrm{Mg}$ implants located in areas further underneath the skin such as implants placed at the muscle area or internal organs [33]. However, rapid measurements seem plausible as readings can be collected at a short response time of $30 \mathrm{~s}$ despite low concentrations (30-400 $\mu \mathrm{M})$ of hydrogen through the skin [34]. Furthermore, $\mathrm{H}_{2}$ sensing has been acknowledged to be a beneficial, non-invasive way to monitor the corrosion of $\mathrm{Mg}$ alloys in-vivo over a large range of corrosion rates. Thus, this places $\mathrm{H}_{2}$ sensing in a favorable position when compared to traditional methods of monitoring corrosion rates [33]. 


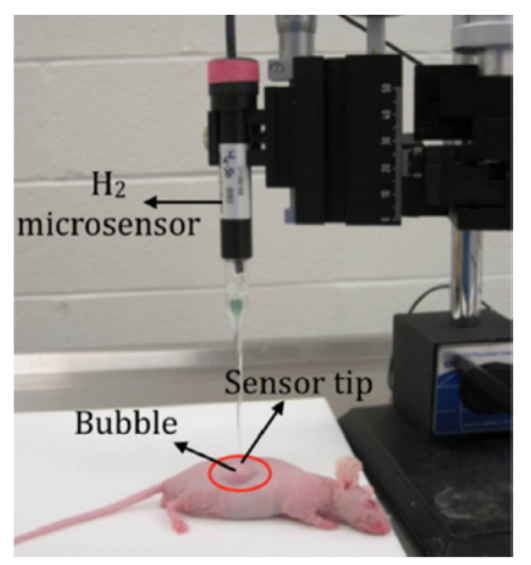

Figure 8. Hydrogen microsensor with direct contact between sensor tip and mice; used to detect and measure hydrogen evolving from an allow of $\mathrm{Mg}$ implanted in the mice [34].

Another type of sensor detection method is a visual biosensor for the detection of hydrogen. According to Zhao et al. [35], "This method of detection is non-invasive, user-friendly, promising and cheap compared to electrochemical detection". Their research has reported a usable visual $\mathrm{H}_{2}$ sensor that allows monitoring of the corrosion process in-vivo. The sensor is constituted of a thin coating on a plastic sheet that changes color when $\mathrm{H}_{2}$ gas is present (Figure 9a). By placing it on the skin where the implant or center of the visible gas cavity is located, detection for corrosion can commence. The sheet will undergo a change of color from gray to dark blue after exposure to hydrogen (Figure 9b). This is due to a metal oxide reduction reaction when the $\mathrm{H}_{2}$ is in the presence of a Pd catalyst. The developed materials could change their color reversibly or irreversibly when $\mathrm{H}_{2}$ gas is present [35]. The indicator of the visual $\mathrm{H}_{2}$ sensor can be thin films comprising transition metal oxides that are 0.2 to 10 microns in thickness or nano-sized with a very thin, uneven coating of a catalyst to initiate its reaction with $\mathrm{H}_{2}$. The color sensitive material within the film only responds to gases that are sufficiently permeable through the skin and react with it, making the visual sensor hydrogen-selective, which is ideal [36].
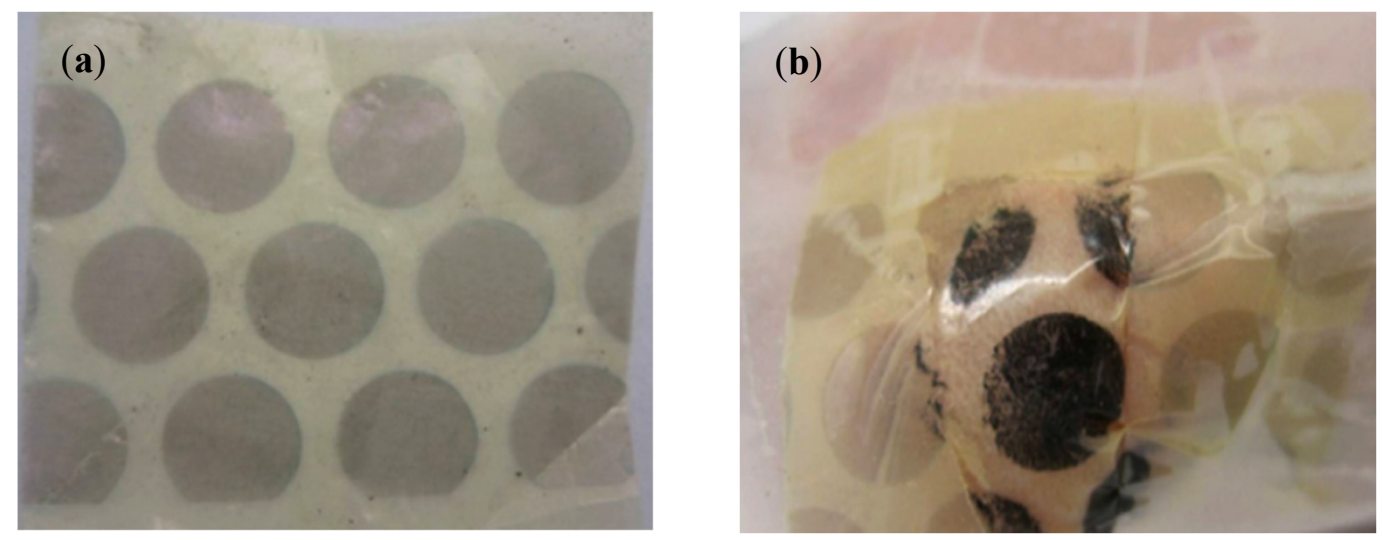

Figure 9. (a) A thin filmed $\mathrm{H}_{2}$ sensor prior to exposure to $\mathrm{H}_{2} ;(\mathbf{b}) \mathrm{H}_{2}$ detected by the film through the mouse's skin [35].

The visual $\mathrm{H}_{2}$ sensor responds in a quantitative manner to the amount of $\mathrm{H}_{2}$ exposed. In-vivo measurements were taken by the visual $\mathrm{H}_{2}$ sensor and a calibrated electrochemical $\mathrm{H}_{2}$ sensor to calibrate the color response of the visual sensor with the electrochemically-measured $\mathrm{H}_{2}$ concentrations. However, it is important to take into consideration that the sensor does not absorb the evolved $\mathrm{H}_{2}$ entirely, as there could be inconsistent barrier between the smooth sensor and the surface of the skin, causing the $\mathrm{H}_{2}$ that is leaving through the skin to escape into the air. Therefore, this would not be a total representation of the amount of $\mathrm{H}_{2}$ released by the corroding implant. A Java-based image 
processing program known as ImageJ was used to quantify the color changes associated with different levels of $\mathrm{H}_{2}$ generated from corroding $\mathrm{Mg}$ alloy implant (Figure 10). The three-dimensional view is useful for assessing the real-time corrosion of specific sections of larger metal implants visually. Due to the current stage of development, a considerable amount of time is still needed for the color change to occur during cases where there are very low levels of $\mathrm{H}_{2}$ infiltrating the skin area [35].

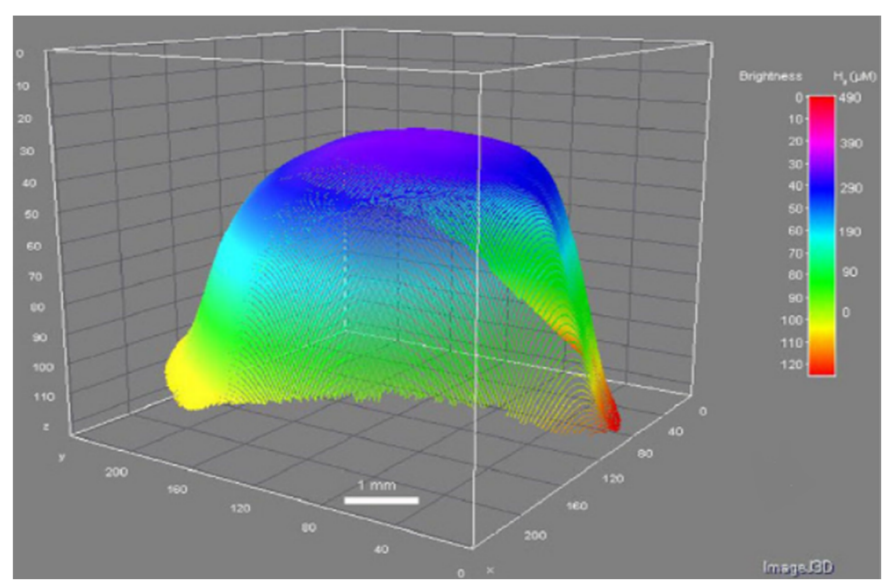

Figure 10. 3D figure of the change in brightness in the $\mathrm{H}_{2}$ sensor area [35].

Di Mei et al. [18] has demonstrated another way to perform hydrogen evolution tests by setting up eudiometers with an electronic balance. This setup (Figure 11) automatically records the corrosion rate values with a USB data logger. Of all the three different electrolytes used, it was determined that the corrosion rate for both commercially-pure $\mathrm{Mg}(\mathrm{CP} \mathrm{Mg})$ and $\mathrm{Mg}-0.8 \mathrm{Ca}$ alloy increases in the following order SBF $<\mathrm{MEM}<\mathrm{NaCl}$. This test allows for the obtaining of results at various time points over the course of the experiment, ensuring that the changes in the rate of corrosion happening over the entire duration of the experiment can be monitored [37].

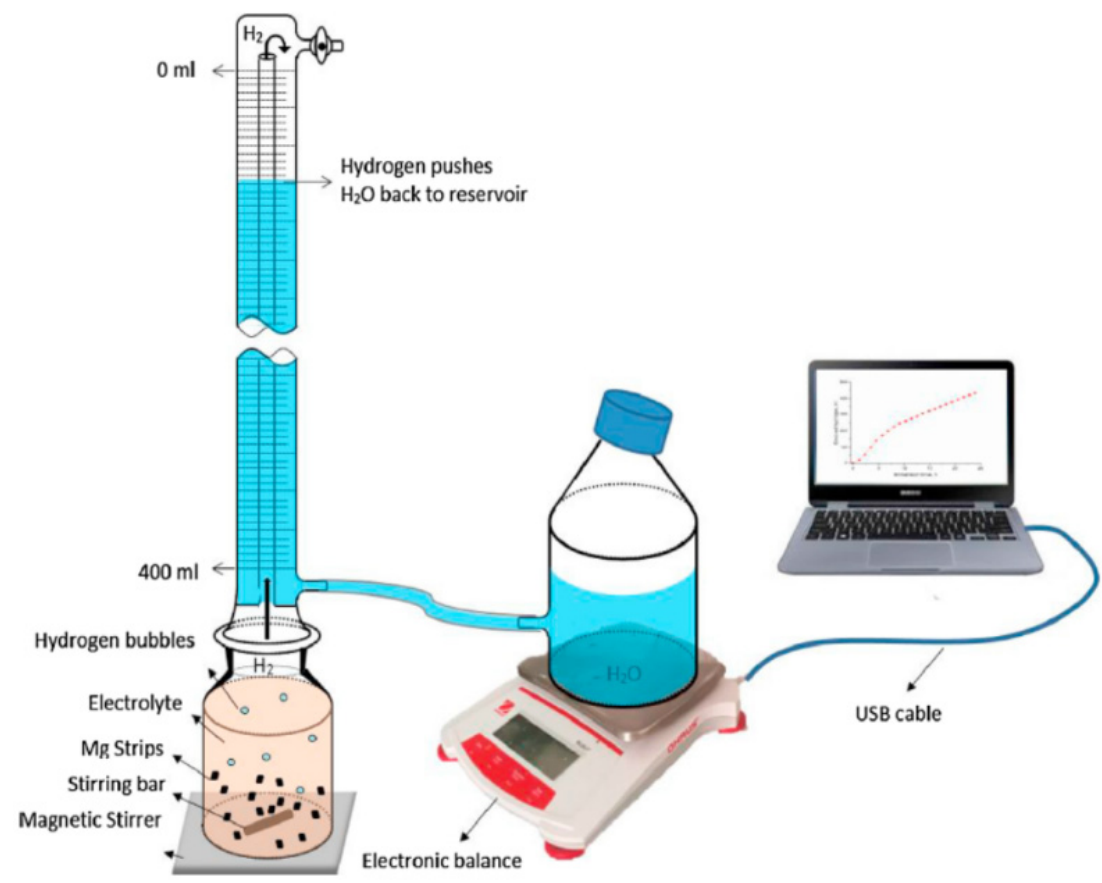

Figure 11. Layout of an hydrogen evolution test experiment involving an eudiometer [18]. 
Another set of tools that can be classified as sensor-based are corrosion sensors that are optically based. These were conceived by having the uncoated area of an optical fiber deposited with specific materials (e.g., nickel-phosphorus layer or Fe-C alloy layer). When there is a loss of coating layer, the optical transmission power will drop [29]. However, its application in real-time still needs verification.

A study conducted by Boutry et al. [38] discussed the concept using biodegradable wireless implants. The idea consists of fabricating a fully biodegradable sensor for in-vivo applications. This concept requires a biomedical implant that can be made of materials that are biodegradable. To further improve the implant from partially biodegradable to completely biodegradable, the antennas/coils used for wireless communication needs to have the ability to fully biodegrade. This may be achieved with the advancement of radiofrequency-driven resistor-inductor-capacitor resonators (RF-driven RLC resonators) constituted from biodegradable metals. These can be constructed by electric discharge machining using biodegradable conductive polymer composites (e.g., polycaprolactone-polypyrrole (PCL-PPy), polylactide-polypyrrole (PLLA-PPy)). These composites are made by compression molding alongside laser-cutting. RLC resonators are frequently used in wireless power and data transmission for short range telemetry.

According to Figure 1 of [38], the partially biodegradable implant is composed of a non-biodegradable block for sensing and electronic purposes while the fully biodegradable coil/antenna (10 MHz operation) is used for data or power transmission outside of the body. In comparison with Figure 2 of [38], the whole sensor is completely biodegradable. The biodegradable metals are used to compose electrical circuits with $\mathrm{Mg}$ being a potential candidate due to its high conductivity and promising biodegradable characteristics [39] whereas PCL or PLLA could be used as material for packaging due to their significant strength and ability to remain mechanically stable for a long time. Unlike Figure 1 of [38], the fully biodegradable implant does not have a data-processing block to regulate the sensor's measured signal. However, Figure 2 of [38] shows an implant that is composed of an RLC resonator that consist of a sensitive sensing layer towards stimulus. The stimulus will cause damping of the resonant frequency of the RLC resonator. Thus, the impedance reflected is related to the signal from the sensor which can be obtained by measuring the external coil's total impedance. On a related note, the data collected are the loaded resonant frequency and loaded quality factor. This data has to be further processed to determine the unloaded parameters which has the real "wanted" sensor signal [38].

\subsection{Microdialysis-Based Monitoring System}

This technique is known for investigating the reactions taking place at the implant's interface and tissue [40]. It is basically used for taking samples where the concentration of the corrosion products formed from the implants will be further evaluated. Microdialysis coupled with a variety of detection techniques such as biosensors has been used for the last three decades to combat issues faced by other corrosion monitoring methods [41]. An experiment was performed under ex-vivo settings by Schumacher et al. [40], where the biocompatibility of pure magnesium was tested by adopting microdialysis in an isolated, perfused bovine udder model. Energy dispersive X-ray spectroscopy (EDX) measurements were then conducted to obtain measurements of the ions formed on the magnesium's surface. They observed that the implant's corrosion did not have a response to inflammation upon direct contact with the tissue. However, these results imply that even when pure magnesium degrades rapidly, it still has good biocompatibility at the interface of the tissue and implant.

Another type of microdialysis-based monitoring method is the set-up developed by Natasha et al. [41] which involves a microdialysis probe with a cotton fabric-based electrochemical device (FED) attached to a potentiostat for conversion of chemical to electrical analysis. One of the main motivations for Natasha et al. to combine microdialysis with a magnesium-reactive biosensor for the monitoring of $\mathrm{Mg}$ corrosion is that the combination of the two systems created a more effective system, which enabled real-time monitoring of the whole corrosion process. This is mainly due to the fact that microdialysis could overcome the biocompatibility issues faced by biosensors while biosensors 
could increase the temporal resolution of the sampling technique. The set-up obtained a pseudo-linear response and interference was lower than $1 \%$ demonstrating that the fabric device has high selectivity. Moreover, only $3 \mu \mathrm{L}$ of fluid sample was required to complete the measurement. Another advantage is that regardless of the location of the implant, a probe of this size can be implanted beneath the skin therefore, enabling measurement of deeper implants. Although further research is still required to optimize the combination of both systems, the current state of this method has the potential to be suitable for real-time in-vivo corrosion monitoring.

In another research from Ulrich et al. [42], an online-microflow capillary flow $(\mu \mathrm{FC})$ is coupled online through a flow injection analyzing system (FIAS) with an inductively-coupled plasma mass spectrometer (ICP-MS) as shown in Figure 12 provided monitoring of the corrosion process at certain intervals with high spatial resolution. This allowed detailed in-situ investigation of corrosion mechanisms and determination of corrosion rates at open circuit potential. Due to ICP-MS's high sensitivity and low detection limits, the alloy ions discharged could be identified at early corrosion stages. However, inaccurate results might be obtained as the bubbles generated from this set-up hinders the contact between the metal surface under exposure and the corrosion media. In addition, the bubbles prevent uniform mixing and dispersal of elements released in the circulating solution within the capillary. This can be solved if a $800 \mu \mathrm{m}$ I.D. large capillary is used. Overall, this method is considered useful for non-homogeneous materials and for determining phase specific processes.

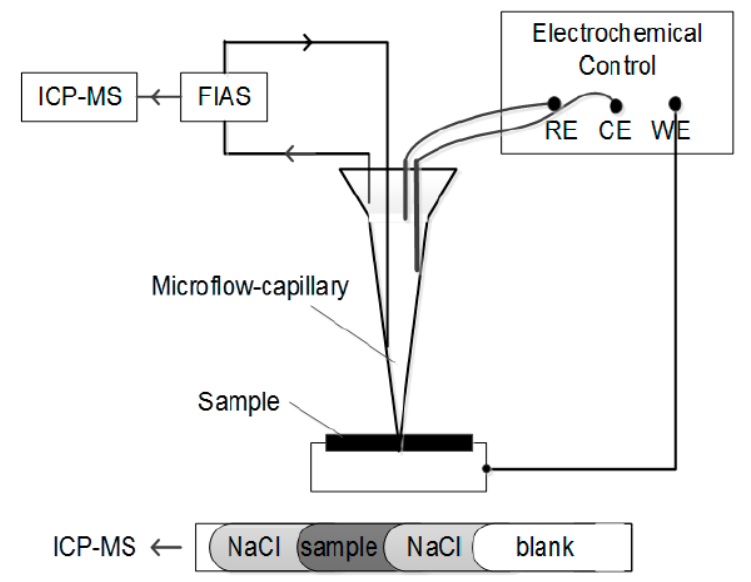

Figure 12. Experiment layout of the $\mu$ FC-FIAS-ICPMS coupled with three-electrode electro-chemical control unit [42].

Further research was conducted by pairing microdialysis with an electrochemical enzymatic biosensor which is well-known for its sensitivity, selectivity, and temporal resolution. The purpose of coupling both tools was to enable in-vivo corrosion monitoring of magnesium in real-time [43]. The fabrication of the biosensor relies on the prerequisite of magnesium ions occurring in enzymatic reactions which enables the required selectivity for this technique. The cloth analytical device (CAD) which was fabricated from cotton cloth could detect magnesium ions at concentrations of 5-1000 $\mu \mathrm{M}$ with a sensitivity of $0.001 \mu \mathrm{A} / \mu \mathrm{M}$ and the detection limit set at $10.16 \mu \mathrm{M}$. Considering that the concentration of $\mathrm{Mg}^{2+}$ in blood serum is usually 0.7 to $1.05 \mathrm{mM}$ and the upper and lower limit are 3 and $9 \mathrm{nmol}$, respectively, the developed CAD can therefore, measure the blood serum's magnesium ion concentration. However, further research is needed to test the interference species and improve the reproducibility of the device. Regardless, CAD still remains a potential candidate for implantation in-vivo during surgery to monitor the corrosion rate of biodegradable Mg implants [43]. 


\section{Discussion of Real-Time In-Vivo/In-Vitro Corrosion Monitoring Methods}

For the comprehension of the fundamentals of biodegradable metal implants corroding in-vivo, the monitoring techniques need to undergo further development in order to have the potential to monitor the corrosion process in-situ. The challenges that are faced by this research is correlating the results from the in-vitro setting to that of the in-vivo setting [4]. Although in-vitro studies give an insight of the behavior of the material under the given condition, it should not be regarded as the final conclusion for recommending a material as an implant, whereas in-vivo tests examine the actual performance of the implant within the animal models [1]. The potentially-available methods used for monitoring corrosion in real-time are still limited, despite its unique capabilities [4] (Table 2).

Table 2. Capabilities and limitations comparison of the real-time in-vivo corrosion monitoring techniques [4].

\begin{tabular}{lll}
\hline \multicolumn{1}{c}{ Technique } & \multicolumn{1}{c}{ Capability } & \multicolumn{1}{c}{ Limitation } \\
\hline $\begin{array}{l}\text { Electrochemical-based } \\
\text { monitoring system }\end{array}$ & $\begin{array}{l}\text { Quantitative measurements and } \\
\text { electrochemical properties can be } \\
\text { obtained in a short period of time. }\end{array}$ & $\begin{array}{l}\text { Limited electrode life leads to inability to } \\
\text { conduct continuous in-vivo corrosion } \\
\text { monitoring affecting quality and accuracy of } \\
\text { data over a period of time. Replacement of } \\
\text { electrodes might also be costly. }\end{array}$ \\
\hline $\begin{array}{l}\text { Microsensor-based } \\
\text { monitoring system }\end{array}$ & $\begin{array}{l}\text { Some corrosion parameters can be } \\
\text { measured accurately (e.g., hydrogen } \\
\text { sensor). It has potential for real-time } \\
\text { applications, but the sensor must be } \\
\text { paired with a data processing device. }\end{array}$ & $\begin{array}{l}\text { Needs special processing software (i.e., image } \\
\text { or signal) to convert the raw data to obtain } \\
\text { desired data. }\end{array}$ \\
\hline $\begin{array}{l}\text { Microdialysis-based } \\
\text { monitoring system }\end{array}$ & $\begin{array}{l}\text { Can be developed for real-time } \\
\text { monitoring when probe is connected to } \\
\text { a data processing device. }\end{array}$ & $\begin{array}{l}\text { Restrictive probe life/performance due to } \\
\text { potential biofouling and difficult to calibrate. }\end{array}$ \\
\hline
\end{tabular}

\section{Technical Improvements}

The proposed new techniques should be developed in order to conduct real-time online monitoring that meets the following criteria [2]:

1. Does not have dangerous consequences on living tissues regardless of dosage or amount of exposure in a continuous time frame.

2. Human-centric in the sense that the instrument can be miniaturized, user-friendly and be able to perform its function regardless of the location of the patient.

3. The analysis on the data obtained should be as soon as possible or, ideally, instantaneously.

The proposed new techniques for monitoring the corrosion process can be divided into three sections.

\subsection{Monitoring Local Changes Surrounding}

As mentioned previously in Section 6.2, one of the potential improvements is the design concept for developing a completely biodegradable implant for in-vivo operation, a wireless biodegradable radio frequency-driven resistor-inductor-capacitor (RLC) resonator that is miniaturized and constructed with biodegradable metals and biodegradable conductive polymer. According to [39], it was concluded that since the resonance peak was still detectable within $6 \mathrm{~mm}$ of muscle and fat tissues when located between the RLC resonator and the measurement coil for both metal and polymer resonators even if largely attenuated, the utilization of these materials to manufacture passive wireless communication devices in biosensors implanted within the body is potentially feasible. At this moment, the most reliable candidate to manufacture the RLC resonators is magnesium due to its high conductivity and exceptional biodegradability. In addition, the rate of corrosion can be altered by alloying the magnesium if faster degradation is required or if the implant's mechanical properties needs to be more 
enhanced. In addition, the biodegradable conducting polymers PCL-PPy and PLLA-PPy have been attracting attention due to their light mass, high flexibility in the manufacturing process, and their compatibility with MRI and X-rays [39]. As of now, the continued development of biodegradable RLC resonators is the first step towards making a completely biodegradable implant for in-vivo scenarios. Boutry et al. [39] acknowledges that a great deal of effort is required before being able to manufacture fully biodegradable biomedical implants while also stating that this progress would be beneficial in the future for the patient's safety and comfort.

Another potential technique of real-time in-vivo corrosion monitoring is a monitoring device that use needle type microelectrode as a biosensor as has been presented and proposed by Cordeiro et al. [44] to measure glucose in the brain. An earlier study that proposed ion-selective micro-electrodes for mapping local activity of $\mathrm{Mg}^{2+}$ and $\mathrm{H}^{+}$is presented in [45]. In the future, an appropriate needle type microelectrode can be developed to measure one or more corrosion rate properties such as weight loss rate of the metal implant and certain ion release. The needle type microelectrode can also be connected to the data acquisition (DAQ) device for automatic timely basis of real-time measurement or monitoring. In detail, the DAQ device will be used for signal conditioning and converting the analog signal to digital signal for further data processing. In order to record and to interpret the raw data into a meaningful data or information, a monitoring device-i.e., computer or laptop with installed driver software and application software-is also necessary for timely saving data as the monitoring can take days or months. The DAQ device connects to a computer through a slot or port and the communication between DAQ device and computer is using a serial bus. An illustration of potential biosensor data acquisition system for real-time in-vivo corrosion monitoring is presented in Figure 13 (adapted from [46]). Potential real-time in-vivo corrosion monitoring has at least the following components: (1) miniaturized biosensor (microelectrode or microsensor); (2) sensor node contains power supply, signal conditioning circuit; and (3) provides the communication hub from sensor and DAQ device to the monitoring system.

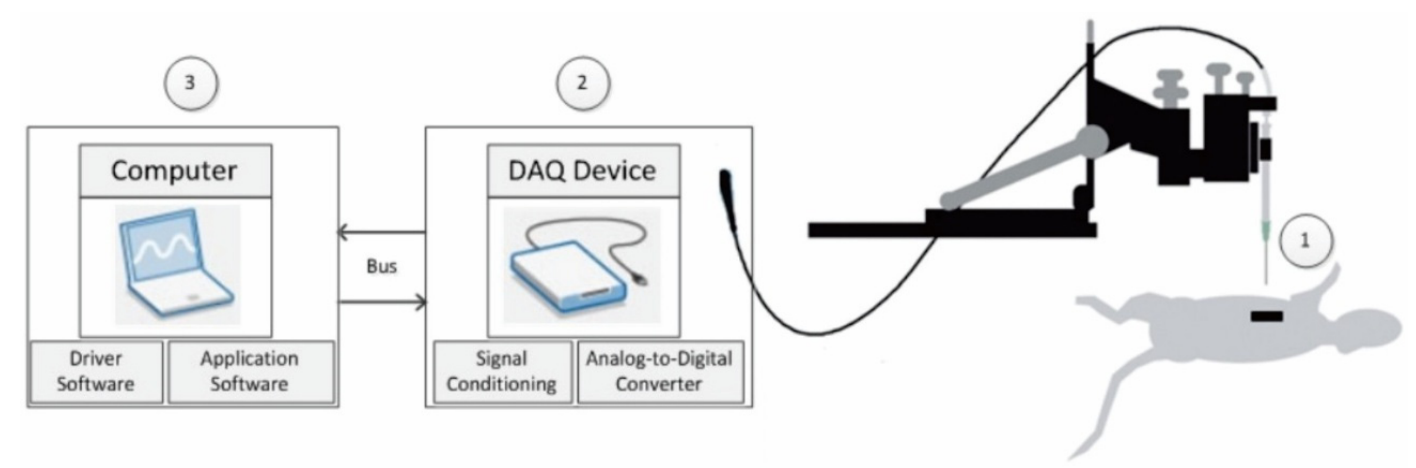

Figure 13. A potential biosensor data acquisition system for real-time in vivo corrosion monitoring: (1) needle-type microelectrode to measure corrosion behavior properties; (2) data acquisition device (DAQ) for signal conditioning and analog-to-digital converter; (3) monitoring device with installed driver software and application software. Adapted from [46].

\subsection{Fabricating an Intelligent Implant}

Referring to Section 8.1, further improvements can be made on the implant and the corrosion monitoring process by making the implant 'intelligent' where it can detect and alter its own degradation. By adopting a cathodic protection technique, the corrosion rate of the implant can be controlled whereby; a reference electrode applies an external current. The cathodic elements are the polarized by the external current to the open circuit potential of the anodes, resulting in the potential across the cathode and anode becoming equal thereby, altering the corrosion current to a smaller volume [29]. 


\subsection{Off-Clinic Point-of-Care Implant Monitoring}

Point-of-care (POC) diagnostics incorporating the microfluidic system was recommended to accelerate diagnostic processes that are time-consuming [47]. Microfluidic technology is easily scalable (integrated system), fast, sensitive, and inexpensive; requiring only a small volume of sample obtained, either invasively or non-invasively. In a POC system, instead of having the patient do a post-check up at the hospital, they can opt to independently monitor their health condition by utilizing a simple diagnostic tool. An example would be a portable device such as those for monitoring blood glucose. The patient's blood samples can be collected directly using a lancet and then the equipment/meter will show the glucose level [2].

However, a non-invasive option would be to analyze saliva. Saliva has been noted as a diagnostic fluid that can be easily obtained. One design such as the lab-on-a-chip technology is a device that measures putative biomarker of periodontal disease present in saliva. Its function is to measure the concentration of MMP-8 (Matrix metalloproteinase-8) in saliva to determine early diagnosis of periodontitis. The instrument is a microchip electrophoretic immunoassay $(\mu \mathrm{CEI})$ allowing direct, automatic measurement of total MMP-8 content in saliva. It was originally designed for chair-side use which relies on a compact reader instrument and a disposable fluidic cartridge. It is also acknowledged that $\mu \mathrm{CEI}$ assays have the capability to measure the said biomarkers rapidly from just a small sample volume thus, making it a diagnostic tool with characteristics applicable to a numerous range of diseases [47]. While the examples mentioned are not applied for monitoring the released ions from metal implants, it is a suggested concept whereby a similar colorimetric-based principle can be adopted to monitor the corroded by-products released from an biodegradable metal implant [2].

\section{Conclusions}

While there have already been several established methods for monitoring the corrosion of a biodegradable metal implant, the suitability still requires further research as each of the corrosion monitoring methods mentioned in this paper has their own limitations that can be improved on. For now, it seems that corrosion monitoring has to adhere to a case-by-case basis (i.e., depending on location of the implant, etc.). One such example is the visual hydrogen sensor; while it is useful in detecting the evolution of hydrogen transdermally, it is not applicable for deeply-implanted implants. Another challenge faced by the biodegradable metal world is the correlation of the results for in-vivo corrosion compared with the tests conducted in-vitro. To compare the different studies and observe a relation between them is time-consuming and a hindrance for efficient progress. Therefore, for further progress to be made, a reliable standard protocol has to be consistently updated to allow for quicker clinical translation to cater to the patient's needs. For the time being, corrosion monitoring methods for in-vivo studies of biodegradable metal implants are derived from those utilized in bio-inert materials (e.g., histology, radiography, etc.) and thus, do not conclude the whole corrosion process of metals. For future development, extensive research on real-time corrosion monitoring and characterization of in-vivo corrosion monitoring is a definite objective.

Author Contributions: Conceptualization, P.Y.Y.C. and W.C.; Methodology, P.Y.Y.C.; Formal analysis, P.Y.Y.C., W.C., and Q.C.; Resources, P.Y.Y.C., Q.C., and W.C.; Writing-original draft preparation, P.Y.Y.C.; Writing-review and editing, P.Y.Y.C., Q.C., W.C., and A.G.; Supervision, Q.C. and W.C.; Funding acquisition, A.G. All authors have read and agreed to the published version of the manuscript.

Funding: This research received no external funding.

Acknowledgments: I would like to express my sincere gratitude towards Wahyu Caesarendra and Quentin Cheok for their guidance and helpful advices throughout this whole project.

Conflicts of Interest: The authors declare no conflict of interest. 


\section{References}

1. Manivasagam, G.; Dhinasekaran, D.; Rajamanickam, A. Biomedical Implants: Corrosion and its Prevention-A Review. Corros. Sci. 2010, 2, 40-54.

2. Paramitha, D.; Ulum, M.F.; Purnama, A.; Wicaksono, D.H.B.; Noviana, D.; Hermawan, H. Monitoring Degradation Products and Metal Ions In Vivo; Elsevier Ltd.: Amsterdam, The Netherlands, 2017.

3. Prakasam, M.; Locs, J.; Salma-Ancane, K.; Loca, D.; Largeteau, A.; Berzina-Cimdina, L. Biodegradable Materials and Metallic Implants-A Review. J. Funct. Biomater. 2017, 8, 44. [CrossRef] [PubMed]

4. Ulum, M.F.; Caesarendra, W.; Alavi, R.; Hermawan, H. In-Vivo Corrosion Characterization and Assessment of Absorbable Metal Implants. Coatings 2019, 9, 282. [CrossRef]

5. Hermawan, H. Updates on the research and development of absorbable metals for biomedical applications. Prog. Biomater. 2018, 7, 93-110. [CrossRef] [PubMed]

6. Chen, Q.; Thouas, G.A. Metallic implant biomaterials. Mater. Sci. Eng. R 2015, 87, 1-57. [CrossRef]

7. Zheng, Y.F.; Gu, X.N.; Witte, F. Biodegradable metals. Mater. Sci. Eng. R 2014, 77, 1-34. [CrossRef]

8. Ali, M.; Hussein, M.A.; Al-Aqeeli, N. Magnesium-based composites and alloys for medical applications: A review of mechanical and corrosion properties. J. Alloys Compd. 2019, 792, 1162-1190. [CrossRef]

9. Walker, M.H.E. Magnesium, Iron and Zinc Alloys, the Trifecta of Bioresorbable Orthopaedic and Vascular Implantation-A Review. J. Biotechnol. Biomater. 2015, 5, 1.

10. Esmaily, M.; Svensson, J.E.; Fajardo, S.; Birbilis, N.; Frankel, G.S.; Virtanen, S.; Arrabal, R.; Thomas, S.; Johansson, L.G. Fundamentals and advances in magnesium alloy corrosion. Prog. Mater. Sci. 2017, 89, 92-193. [CrossRef]

11. Noviana, D.; Paramitha, D.; Ulum, M.F.; Hermawan, H. The effect of hydrogen gas evolution of magnesium implant on the postimplantation mortality of rats. J. Orthop. Transl. 2016, 5, 9-15. [CrossRef]

12. Reifenrath, J.; Krause, A.; Bormann, D.; Windhagen, H. Profound differences in the in-vivo-degradation and biocompatibility of two very similar rare-earth containing Mg-alloys in a rabbit model. Materialwissenschaft und Werkstofftechnik 2010, 41, 1054-1061. [CrossRef]

13. Cheng, P.; Zhao, C.; Han, P.; Ni, J.; Zhang, S.; Zhang, X.; Chai, Y. Site-Dependent Osseointegration of Biodegradable High-Purity Magnesium for Orthopedic Implants in Femoral Shaft and Femoral Condyle of New Zealand Rabbits. J. Mater. Sci. Technol. 2016, 32, 883-888. [CrossRef]

14. Li, N.; Zheng, Y. Novel Magnesium Alloys Developed for Biomedical Application: A Review. J. Mater. Sci. Technol. 2013, 29, 489-502. [CrossRef]

15. Drelich, A.J.; Zhao, S.; Guillory, R.J.; Drelich, J.W.; Goldman, J. Long-term surveillance of zinc implant in murine artery: Surprisingly steady biocorrosion rate. Acta Biomater. 2017, 58, 539-549. [CrossRef]

16. Razavi, M.; Fathi, M.; Savabi, O.; Vashaee, D.; Tayebi, L. In vivo assessments of bioabsorbable AZ91 magnesium implants coated with nanostructured fluoridated hydroxyapatite by MAO/EPD technique for biomedical applications. Mater. Sci. Eng. C 2015, 48, 21-27. [CrossRef]

17. Yu, W.; Zhao, H.; Ding, Z.; Zhang, Z.; Sun, B.; Shen, J.; Chen, S.; Zhang, B.; Yang, K.; Liu, M.; et al. In vitro and in vivo evaluation of $\mathrm{MgF} 2$ coated AZ31 magnesium alloy porous scaffolds for bone regeneration. Colloids Surfaces B Biointerfaces 2017, 149, 330-340. [CrossRef]

18. Mei, D.; Lamaka, S.V.; Feiler, C.; Zheludkevich, M.L. The effect of small-molecule bio-relevant organic components at low concentration on the corrosion of commercially pure $\mathrm{Mg}$ and $\mathrm{Mg}-0.8 \mathrm{Ca}$ alloy: An overall perspective. Corros. Sci. 2019, 153, 258-271. [CrossRef]

19. Witte, F.; Fischer, J.; Nellesen, J.; Crostack, H.A.; Kaese, V.; Pisch, A.; Beckmann, F.; Windhagen, H. In vitro and in vivo corrosion measurements of magnesium alloys. Biomaterials 2006, 27, 1013-1018. [CrossRef]

20. Sanchez, A.H.M.; Luthringer, B.J.C.; Feyerabend, F.; Willumeit, R. Mg and Mg alloys: How comparable are in vitro and in vivo corrosion rates? A review. Acta Biomater. 2015, 13, 16-31. [CrossRef]

21. Hofstetter, J.; Martinelli, E.; Weinberg, A.M.; Becker, M.; Mingler, B.; Uggowitzer, P.J.; Löffler, J.F. Assessing the degradation performance of ultrahigh-purity magnesium in vitro and in vivo. Corros. Sci. 2015, 91, 29-36. [CrossRef]

22. Hiromoto, S.; Inoue, M.; Taguchi, T.; Yamane, M.; Ohtsu, N. In vitro and in vivo biocompatibility and corrosion behaviour of a bioabsorbable magnesium alloy coated with octacalcium phosphate and hydroxyapatite. Acta Biomater. 2015, 11, 520-530. [CrossRef] [PubMed] 
23. Lin, W.; Qin, L.; Qi, H.; Zhang, D.; Zhang, G.; Gao, R.; Qiu, H.; Xia, Y.; Cao, P.; Wang, X.; et al. Long-term in vivo corrosion behavior, biocompatibility and bioresorption mechanism of a bioresorbable nitrided iron scaffold. Acta Biomater. 2017, 54, 454-468. [CrossRef] [PubMed]

24. Duffin, M. Closing the gap. Manag. Serv. Qual. Int. J. 1992, 2, 77-79. [CrossRef]

25. Pedeferri, P.M.; Pietro, L.L. Corrosion Science and Engineering; Springer: Cham, Switzerland, 2018.

26. John, K.H.; Zhang, X.J. Electrical Transducers: Electrochemical Sensors and Semiconductor Molecular Sensors; Elsevier Ltd.: Amsterdam, The Netherlands, 2014.

27. Wang, J.; Jang, Y.; Wan, G.; Giridharan, V.; Song, G.L.; Xu, Z.; Koo, Y.; Qi, P.; Sankar, J.; Huang, N.; et al. Flow-induced corrosion of absorbable magnesium alloy: In-situ and real-time electrochemical study. Corros. Sci. 2015, 104, 277-289. [CrossRef]

28. Doepke, A.; Kuhlmann, J.; Guo, X.; Voorhees, R.T.; Heineman, W.R. A system for characterizing Mg corrosion in aqueous solutions using electrochemical sensors and impedance spectroscopy. Acta Biomater. 2013, 9, 9211-9219. [CrossRef]

29. Yun, Y.; Dong, Z.; Lee, N.; Liu, Y.; Xue, D.; Guo, X.; Kuhlmann, J.; Doepke, A.; Halsall, H.B.; Heineman, W.; et al. Revolutionizing biodegradable metals. Mater. Today 2009, 12, 22-32. [CrossRef]

30. Yang, Y.; Scenini, F.; Curioni, M. A study on magnesium corrosion by real-time imaging and electrochemical methods: Relationship between local processes and hydrogen evolution. Electrochim. Acta 2016, 198, 174-184. [CrossRef]

31. Liu, Y.; Liu, X.; Zhang, Z.; Farrell, N.; Chen, D.; Zheng, Y. Comparative, real-time in situ monitoring of galvanic corrosion in Mg-Mg $2 \mathrm{Ca}$ and Mg-MgZn 2 couples in Hank's solution. Corros. Sci. 2019, 161, 108-185. [CrossRef]

32. Zhao, D.; Wang, T.; Guo, X.; Kuhlmann, J.; Doepke, A.; Dong, Z.; Shanov, V.N.; Heineman, W.R. Monitoring Biodegradation of Magnesium Implants with Sensors. JOM 2016, 68, 1204-1208. [CrossRef]

33. Zhao, D.; Wang, T.; Nahan, K.; Guo, X.; Zhang, Z.; Dong, Z.; Chen, S.; Chou, D.T.; Hong, D.; Kumta, P.N.; et al. In vivo characterization of magnesium alloy biodegradation using electrochemical $\mathrm{H} 2$ monitoring, ICP-MS, and XPS. Acta Biomater. 2017, 50, 556-565. [CrossRef]

34. Zhao, D.; Wang, T.; Kuhlmann, J.; Dong, Z.; Chen, S.; Joshi, M.; Salunke, P.; Shanov, V.N.; Hong, D.; Kumta, P.N.; et al. In vivo monitoring the biodegradation of magnesium alloys with an electrochemical $\mathrm{H} 2$ sensor. Acta Biomater. 2016, 36, 361-368. [CrossRef]

35. Zhao, D.; Wang, T.; Hoagland, W.; Benson, D.; Dong, Z.; Chen, S.; Chou, D.T.; Hong, D.; Wu, J.; Kumta, P.N.; et al. Visual H2 sensor for monitoring biodegradation of magnesium implants in vivo. Acta Biomater. 2016, 45, 399-409. [CrossRef]

36. Manufacturing, F.U.S. Hydrogen Gas Indicator System. U.S. Patent 6,895,805, 24 May 2005.

37. Kirkland, N.T.; Birbilis, N.; Staiger, M.P. Assessing the corrosion of biodegradable magnesium implants: A critical review of current methodologies and their limitations. Acta Biomater. 2012, 8, 925-936. [CrossRef]

38. Boutry, C.M.; Chandrahalim, H.; Streit, P.; Schinhammer, M.; Haenzi, A.C.; Hierold, C. Towards biodegradable wireless implants. Philos. Trans. R. Soc. 2012, 370, 2418-2432. [CrossRef]

39. Boutry, C.M.; Chandrahalim, H.; Streit, P.; Schinhammer, M.; Hänzi, A.C.; Hierold, C. Characterization of miniaturized RLC resonators made of biodegradable materials for wireless implant applications. Sensors Actuators A Phys. 2013, 189, 344-355. [CrossRef]

40. Schumacher, S.; Stahl, J.; Bäumer, W.; Seitz, J.M.; Bach, F.W.; Petersen, L.J.; Kietzmann, M. Ex vivo examination of the biocompatibility of biodegradable magnesium via microdialysis in the isolated perfused bovine udder model. Int. J. Artif. Organs 2011, 34, 34-43. [CrossRef]

41. Natasha, M.S.; Malon, R.S.P.; Wicaksono, D.H.B.; Córcoles, E.P.; Hermawan, H. Monitoring magnesium degradation using microdialysis and fabric-based biosensors. Sci. China Mater. 2018, 61, 643-651. [CrossRef]

42. Ulrich, A.; Ott, N.; Tournier-fillon, A.; Homazava, N.; Schmutz, P. Spectrochimica Acta Part B Investigation of corrosion behavior of biodegradable magnesium alloys using an online-micro-flow capillary flow injection inductively coupled plasma mass spectrometry setup with electrochemical control. Spectrochim. Acta Part B At. Spectrosc. 2011, 66, 536-545. [CrossRef]

43. Natasha, S.; Malon, R.S.P.; Wicaksono, D.H.B.; Córcoles, E.P.; Hermawan, H. Electrochemical detection of magnesium ions using magnesium biosensor. Eur. Cells Mater. 2013, 26, 130000. 
44. Cordeiro, C.A.; Sias, A.; Koster, T.; Westerink, B.H.C.; Cremers, T.I.F.H. In vivo 'real-time' monitoring of glucose in the brain with an amperometric enzyme-based biosensor based on gold coated tungsten (W-Au) microelectrodes. Sensors Actuators, B Chem. 2018, 263, 605-613. [CrossRef]

45. Lamaka, S.V.; Karavai, O.V.; Bastos, A.C.; Zheludkevich, M.L.; Ferreira, M.G.S. Monitoring local spatial distribution of $\mathrm{Mg} 2+, \mathrm{pH}$ and ionic currents. Electrochem. Commun. 2008, 10, 259-262. [CrossRef]

46. Kiskova, T.; Steffekova, Z.; Karasova, M.; Kokosova, N. pH Monitoring of Urine and Tumor Microenvironments in Rats. Available online: https://www.presens.de/knowledge/publications/applicationnote/ph-monitoring-of-urine-and-tumor-microenvironments-in-rats-655 (accessed on 20 April 2020).

47. Herr, A.E.; Hatch, A.V.; Throckmorton, D.J.; Tran, H.M.; Brennan, J.S.; Giannobile, W.V.; Singh, A.K. Microfluidic immunoassays as rapid saliva-based clinical diagnostics. Proc. Natl. Acad. Sci. USA 2007, 104, 5268-5273. [CrossRef]

(C) 2020 by the authors. Licensee MDPI, Basel, Switzerland. This article is an open access article distributed under the terms and conditions of the Creative Commons Attribution (CC BY) license (http://creativecommons.org/licenses/by/4.0/). 